\title{
Influence of Adult Knee Height, Age at First Birth, Migration, and Current Age on Adult Physical Function of Bangladeshi Mothers and Daughters in the United Kingdom and Bangladesh
}

\author{
Barry Bogin, ${ }^{1}$ Diane Harper, ${ }^{1}$ Joy Merrell, ${ }^{2}$ Jasmin Chowdhury, ${ }^{2}$ Michael Heinrich, ${ }^{3}$ \\ Vanja Garaj, ${ }^{4}$ Bablin Molik, ${ }^{5}$ and Janice L. Thompson ${ }^{6}$ \\ ${ }^{1}$ Centre for Global Health \& Human Development, School of Sport, Exercise and Health Sciences, \\ Loughborough University, Loughborough LE11 3TU, UK \\ ${ }^{2}$ College of Human and Health Sciences, Swansea University, Singleton Park, Swansea SA2 8PP, UK \\ ${ }^{3}$ Centre for Pharmacognosy and Phytotherapy, UCL School of Pharmacy, 29-39 Brunswick Square, London WC1N 1AX, UK \\ ${ }^{4}$ School of Engineering and Design, Brunel University, Uxbridge UB8 3PH, UK \\ ${ }^{5}$ Sight Cymru, Bradbury House, Park Buildings, Pontypool NP4 6JH, UK \\ ${ }^{6}$ University of Birmingham, School of Sport, Exercise and Rehabilitation Sciences, Edgbaston, Birmingham B15 2TT, UK
}

Correspondence should be addressed to Barry Bogin; b.a.bogin@lboro.ac.uk

Received 12 October 2013; Accepted 6 February 2014; Published 7 April 2014

Academic Editor: Benjamin Campbell

Copyright ( $\odot 2014$ Barry Bogin et al. This is an open access article distributed under the Creative Commons Attribution License, which permits unrestricted use, distribution, and reproduction in any medium, provided the original work is properly cited.

In the United Kingdom, Bangladeshi women have the lowest self-reported levels of physical activity and some of the highest levels of metabolic disease of all ethnic groups. To better understand these risks for poor health we employed life course and intergenerational hypotheses to predict lower body physical function in a sample of 121 Bangladeshi mothers (40-70 years old) and one of their adult daughters (17-36 years old) living in Bangladesh or in the UK. For the mothers, older age and shorter knee height predicted reduced lower body physical function. Knee height is a biomarker of nutrition and health status between birth and puberty. Age at first birth did not have a significant effect. For daughters, older age and migration to the UK predicted reduced lower body physical function. We controlled for total stature and fatness in all analyses. UK-born daughters were taller than BD-born daughters living in the UK, mostly due to differences in knee height. These new findings support previous research indicating that early life health and adequate nutritional status, along with appropriate adult physical activity and diet, may decrease risks for poor physical function, morbidity, and premature mortality.

\section{Introduction}

The life course hypothesis for adult health and disease posits that modifiable environmental influences on growth, development, and maturation during preadult life has correlates with adult health, rates of aging, and mortality [1-6]. It is also well recognized that nutrition and health conditions of mothers have intergenerational consequences which affect the phenotypes of their offspring. Emanuel and colleagues called this the intergenerational influences hypothesis [7-9]. Today, there is ample evidence in favour of life course and intergenerational influences on the risks for adult diseases, including overweight/obesity, atherosclerosis, hypertension, type 2 diabetes, certain dementias, and other noncommunicable metabolic disorders [10-13].

Risks for these conditions accrue from a variety of sources, including modifiable factors, such as nutrition, physical activity, exposure to infection, tobacco, alcohol, and industrial toxicants, as well as migration from place to place and chance events acting across the life course which may improve or impair, "...the effectiveness of body systems for maintenance and repair" [14, page 717]. After about age 30 years, the accumulation of environmental insults interacts with the intrinsic decline in one's capacity to achieve appropriate responses to new challenges, resulting in an inexorable increased risk of many physical and cognitive 
disorders with time [15]. The best defense against these ageassociated risks seems to be a greater accumulation of reserve capacity, also called embodied capital or resilience, during growth and development $[14,16-20]$. Reserve capacity is defined as those somatic resources possessed by an organism which exist above the minimum required for survival and reproduction. There is often an inverse relationship between reserve capacity and risk for illness, disability, and death. For human beings, reserve capacity is often measured in terms of skeletal growth, bone density, body mass, body composition, physical function (e.g., grip strength, and gait speed), and cognition (e.g., crystalized and fluid memory).

In this paper we employ the life course hypothesis and intergenerational influences hypothesis to understand variation in reserve capacity as measured by physical function for a sample of Bangladeshi mothers and daughters living in the United Kingdom (UK) and Bangladesh (BD). Our focus on Bangladeshi women is important because Bangladeshi women living in the UK, elsewhere in Europe, and in North America have low levels of physical activity and suffer from high prevalence of obesity, diabetes, and other metabolic disorders [22, 23]. Little is known about their physical function status. As a proxy for reserve capacity, measures of physical function, such as gait speed balance, and leg strength, may be used to classify subjects across a wide range of function and identify nondisabled persons who may be at higher risk for a variety of adverse outcomes as they age. In addition, measures of physical function may be used in crossnational and cross-cultural studies of health and aging [21, 24] because these functions are universal to all people.

We present a method, based on the measurement of adult knee height, to quantify the nutritional and health status of these women when they were prepubertal girls. We also analyse biosocial tradeoffs between prepubertal growth, migration from Bangladesh to the United Kingdom, and age at first birth in relation to adult physical function. Our conceptual model is based on two lines of investigation. The first is the growing body of research showing that greater adult knee height reflects better nutrition and health between birth and puberty, which translates into greater preadult reserve capacity and delays the onset of aging-related declines in health and cognition [25-28].

The rationale for using adult knee height as a biomarker for early life nutrition and health is based on that fact that between birth and puberty the legs grow relatively faster than the upper body, a pattern called the cephalocaudal gradient in growth. We should expect, therefore, leg length to be relatively longer in populations that live under more advantaged circumstances because better nutrition and health will allow for more leg growth in the early years of life. This was first demonstrated to be the case for total leg length by studies of child growth in Europe following World War II [29] and has since been replicated in many studies. This research is reviewed in Bogin and Varela-Silva [30]. A more recent study of the United States population also supports the use of leg length as a biomarker of health and environmental stress for people between birth and puberty [31]. This study reported that variation in birth weight and variation in the growth of leg length relative to stature between the ages of 2 to 8 years are independent. The results suggest that birth weight and leg length represent independent information on prenatal and postnatal environmental quality.

Another recent study by Azcorra et al. [32] supports the use of leg length as a biomarker of early postnatal quality of life. The authors conducted an intergenerational study of grandmothers, their adult daughters, and their 6-8-year-old grandchildren of Maya ethnicity living in Merida, Mexico. All of these Maya participants were of low socioeconomic status and showed evidence of nutritional inadequacies and poor health in terms of short stature. The researchers found that $29 \%$ of the children had short leg length $(\leq 2 \mathrm{SD}$ of an international reference), but only $7 \%$ had short sitting heights. They interpreted this to mean that the short stature of the children was due primarily to reduced growth of the tibia and femur. In addition, significant correlations in height, sitting height, and leg length (all standardized for age and sex) were found in mother-to-child and grandmother-to-mother pairs. The strongest correlations were for leg length. The authors suggest that these intergenerational correlations are due to persistent environmental adversity resulting in growth deficits, especially for leg length in the children.

Knee height may be an even more sensitive biomarker than total leg length. The tibia is the most distal long bone of the human body (excluding foot metatarsals), and its growth in length is the slowest relative to total stature [30]. This should make the growth of the tibia more sensitive to environmental quality than the growth of the femur. The value of tibial length as a sensitive biomarker of prepubertal health was shown in a study of lowland versus highland Peruvians aged 6-14 years old [33]. The highland sample was exposed to greater amounts of stress, such as hypoxia, cold temperatures, or nutritional deficiencies, than the lowland sample. Highlanders had significantly shorter limbs, especially the tibia and radius, than the participants who experienced less of these stresses (e.g., living at low altitude).

Pomeroy and colleagues measured tibia length from surface landmarks of this bone. This is often difficult to do in many populations, for example, because of modesty required by participants. Knee height $(\mathrm{KH})$ may serve as a proxy for tibia length. The contribution of the ankle (tarsal bones) to knee height is relatively minor compared to the contribution of the tibia. Knee height is also valuable as a biomarker of health and nutrition status between birth and age 10 years because $\mathrm{KH}$ is relatively constant from early adulthood until death. KH does not "shrink" with age as does total stature, due to compression of vertebral discs and other joints. For all of these reasons, the measurement of $\mathrm{KH}$ in adults, especially older people, provides a proxy for total skeletal growth and the accumulation of somatic reserve capacity early in life [3436]. A larger and more robust skeleton, along with greater total somatic reserves of muscle associated with a larger skeleton, are likely to allow for greater physical performance through the adult years of life $[2,14,20]$.

The second basis for our conceptual model comes from research suggesting that age at first birth may serve as the transition between somatic investment in a woman's own body and the diversion of her nutritional and health resources toward her offspring $[37,38]$. A pregnant woman will likely 
receive food and assistance from several family members [39], but all the direct physiological investment in a pregnancy must derive from the women's body. In cases when a pregnant woman has insufficient body reserves or intake of needed resources (including food and psychosocial resources), there will be a tradeoff between the needs of the woman and the needs of her fetus. This may cause compromised metabolism, physiology, and behaviour, as well as emotional distress, resulting in increased risks of diseases [38]. This tradeoff will tend to accelerate the loss of reserve capacity, accelerate somatic aging, and decrease levels of physical function as the women age [40].

\section{Hypotheses}

Using these conceptual models we test two life course hypotheses for our sample of adult Bangladeshi mothers: (1) greater knee height predicts a higher physical function score and (2) a later age at first birth predicts a higher physical function score. For their daughters we test the life course hypotheses that (3) greater knee height predicts a higher physical function score and (4) migration from Bangladesh to the UK predicts a lower physical function score. Finally, we test the intergenerational influences hypotheses that (5) greater mother's $\mathrm{KH}$ and (6) a later age at mother's first birth predict a higher physical function score of the daughter.

\section{Methods}

Project MINA-Migration, Nutrition and Ageing across the Lifecourse in Bangladeshi Families: A Transnational Perspective-was a cross-sectional study that investigated two generations of Bangladeshi women in the Cardiff, UK and Sylhet Division, BD (http://projectmina.org/). MINA employed a participatory approach to involve community members and leaders in all stages of the project. Participant recruitment depended on this approach, as many first generation women are not fluent in English and may be socially isolated from the dominant British society [41, 42]. UK community members fluent in Bangla and Sylheti were employed as coresearchers who assisted the authors of this paper with recruitment, data collection, translation of interviews, interpretation of findings, and dissemination. Sampling was purposive, based on Bangladeshi ethnicity, age limits, place of residence, and the research budget. Recruitment of participants was by direct contact via community researchers and by word-of-mouth through snowball sampling. Both in Bangladesh and in the UK, our goal was to recruit participants across a range of socioeconomic statuses and places of origin in Bangladesh (city, towns, and villages). We also wanted to recruit UK-living daughters who were born in either Bangladesh or born in the UK. In this paper we analyse the entire sample and we do not make distinctions based on socioeconomic status or places of origin in Bangladesh. We do include migration from Bangladesh versus birth in the UK as a variable for analysis.

The UK sample included 40 mothers ( $40-70$ years) and one of their UK-living adult daughters (17-36 years, $n=$ 37 as 3 daughters who were recruited did not subsequently participate). All of the mothers were born in the Sylhet District. The daughters were either born in the UK $(n=20)$ or in $\mathrm{BD}(n=17)$. All were living in or near Cardiff, Wales. The 2011 census indicates that the Bangladeshi population living in Cardiff is 4,838 , or approximately $45 \%$ of the Bangladeshis living in Wales [43].

The Bangladesh sample included 22 mother-daughter pairs of the same two age groups, all born in Sylhet District. Geographic locations of the samples are shown in Figure 1.

According to the 2011 census, the UK Bangladeshi population resident in England and Wales is 447,201, or 0.8\% of the total UK population; this is an increase of just over $50 \%$ from the previous census in 2001 [43]. Additionally, this group is reported to be one of the most deprived populations in the UK, having high rates of unemployment, social deprivation, and low rates of education [44]. They also have poorer self-reported and measured health status indicated by higher rates of disability, centralised obesity, and chronic diseases such as type 2 diabetes and cardiovascular disease (British Heart Foundation 2013, http://www.bhf.org.uk/heart-health/prevention/ethnicity/ bangladeshi.aspx). Older Bangladeshi women are particularly affected as they play a lead role in caretaking for multiple generations within relatively large extended families and many struggle to cope with the complex challenges of ageing, poverty, racism, and social exclusion. The MINA project builds upon previous research related to migration and ageing amongst UK Bangladeshis living in the Tower Hamlets region of East London $[45,46]$. That community is relative large and provides a socially and linguistically insulated environment for Bangladeshis in the UK. MINA provided new insights into specifically food, nutrition, and their interactions with ageing and migration amongst UK Bangladeshi families who are living in communities outside of Tower Hamlets, that is, in regions where Bangladeshis are a distinct minority and do not have well-developed systems for sociocultural support.

\section{Data Collection and Measurements}

In Cardiff, data were collected via community events that included lunch, physical activities such as Extend and Bollywood dancing, Indian head massage, and stations providing information on health and social care services. Events took place in November 2009, March 2010, and June 2010. These events were popular amongst the participants and helped to ensure that recruitment targets were achieved. MINA has also had a positive impact on training Bangladeshi researchers living in the UK. The project employed two Bangladeshi research assistants, one Bangladeshi postdoctoral fellow, and employed and trained 11 Bangladeshi community researchers from the Cardiff and Swansea areas. Further information and photographs about the events and the MINA project are available at two websites: (1) http://www.newdynamics.group.shef.ac.uk/mina.html and (2) http://projectmina.org/.

In Sylhet all data were collected in the home environment during January and February 2010. In both the UK and BD all 


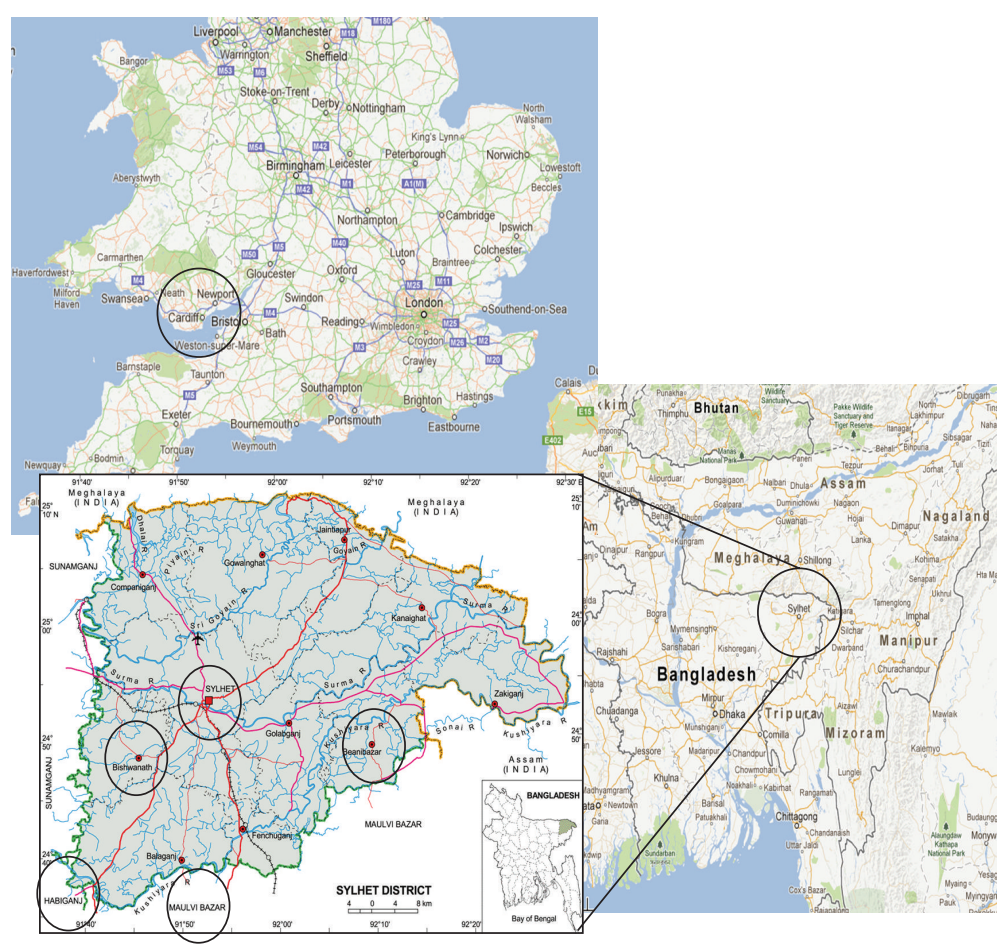

FIGURE 1: MINA project sample sites: Cardiff, UK, and Sylhet, Bangladesh. Enlargement of Sylhet District shows specific location of sample sites (original map; created from http://sketchmap.co.uk/). Two of the sites lie at the border of the Sylhet District but within the Sylhet Division, which is a larger geopolitical entity and consists of four districts-Sylhet, Habiganj, Moulvibazar, and Sunamganj. Sylhet District and Division encompasses much geographic, economic, and social variations.

anthropometric data were assessed by the same experienced member of the team (JT). Weight was measured to the nearest $0.5 \mathrm{~kg}$ using a portable digital scale, waist circumference was measured at the most narrow point to the nearest $0.1 \mathrm{~cm}$ using a flexible tape measure, and height and sitting height were measured to the nearest $0.1 \mathrm{~cm}$ using standard protocols and Harpenden anthropometric equipment. Our measure of knee height $(\mathrm{KH})$ involved placing the plantar surface of the participant's foot on the floor, without shoes or socks, and then measuring the distance from the floor to the proximal border of the patella (top of the knee cap) with the participant seated and the lower leg as perpendicular to the floor as possible (90 degree angle to the floor). This method avoids contamination of the measurement with soft tissue, especially fat, which has been shown to artificially inflate other linear skeletal measurements [47].

Physical function was assessed using the short physical performance battery or SPPB $[21,48,49]$. The SPPB measures lower body physical function in terms of balance, gait speed, strength, and endurance in terms of ability to stand with the feet together in the side-by-side, semitandem, and tandem positions, time to walk four meters, and time to rise from a chair and return to the seated position 5 times (Figure 2). A lower score on the SPPB indicates worse physical function.

The SPPB reflects gait speed, chair-stand, and balance, each of which may be a substantively different measure of lower body physical performance. To better understand the contribution of each of the components of the SPPB we computed their individual results and statistically tested the difference between the same subtest categorical scores across groups of participants. This type of statistical contrast may be done within the SPPB subtests, but the subtests cannot be statistically compared against each other (J. Guralnik, personal communication).

Participants were interviewed face-to-face in English, Bangla, or Sylheti languages and completed a questionnaire which included individual and family demographic characteristics and history of migration (e.g., place of birth, age of migration from $\mathrm{BD}$ to the UK, and places lived in the UK). All interviewers were carefully trained and their reliability assessed by several authors (Joy Merrell, Jasmin Chowdhury, Bablin Molik, and Janice L. Thompson). Other biological and social variables were collected but are not analysed in this paper.

\section{Statistical Analysis}

Descriptive statistics were calculated for all variables by the categories of generation (mother or daughter), country of birth, and current country of residence. $t$-tests, proportion tests, or ANOVA were used to estimate statistical significance between comparison groups. A power analysis for $t$ test was calculated following data collection. Based on the anthropometric variables of height and weight the power analysis found that a minimum sample size of $n=14$ provides a power goal of 0.80 to detect a significant between two groups at $P=0.05$. To test our hypotheses, forward stepwise multiple regression was used to assess the relative 
Short physical performance battery

(1)

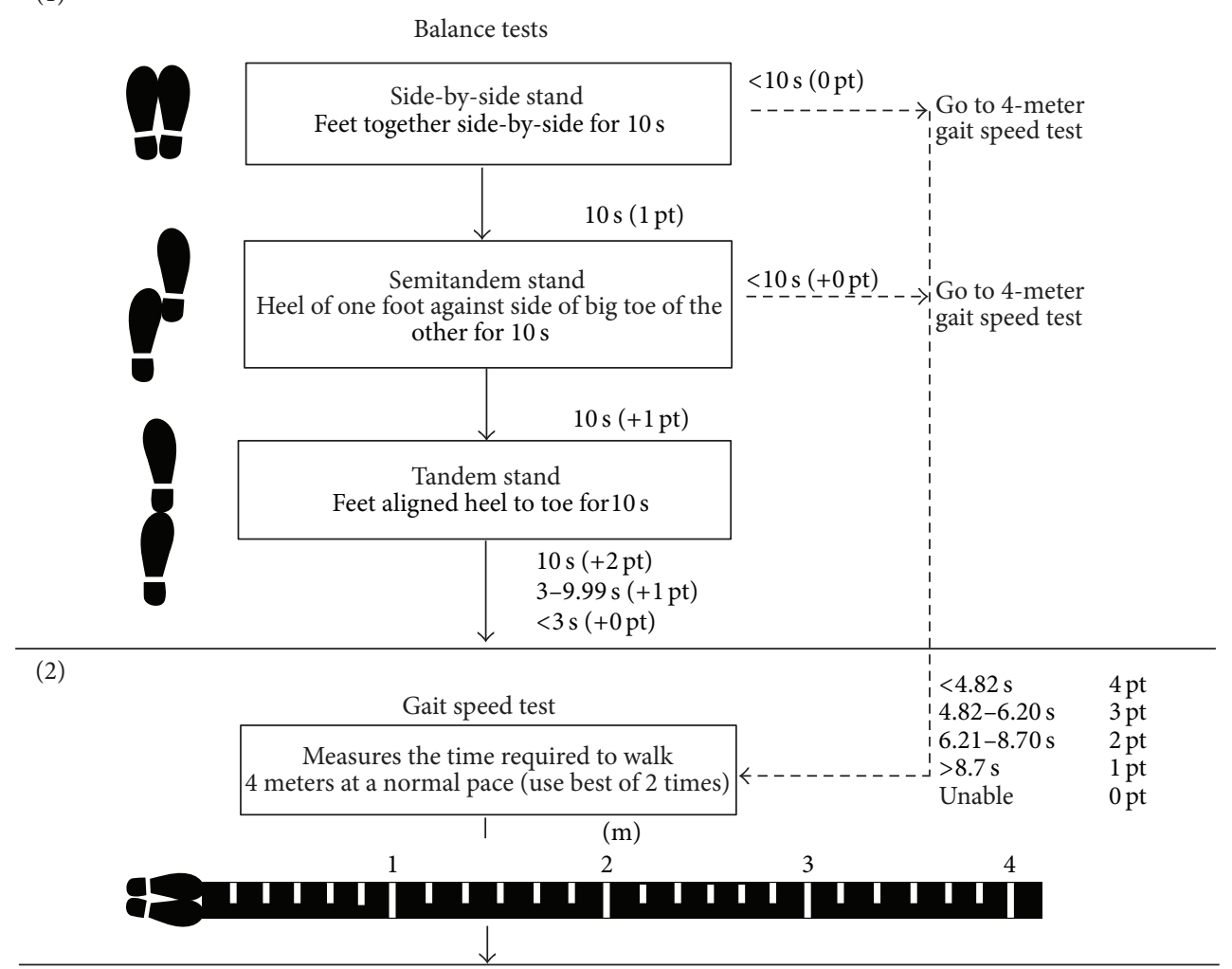

(3)

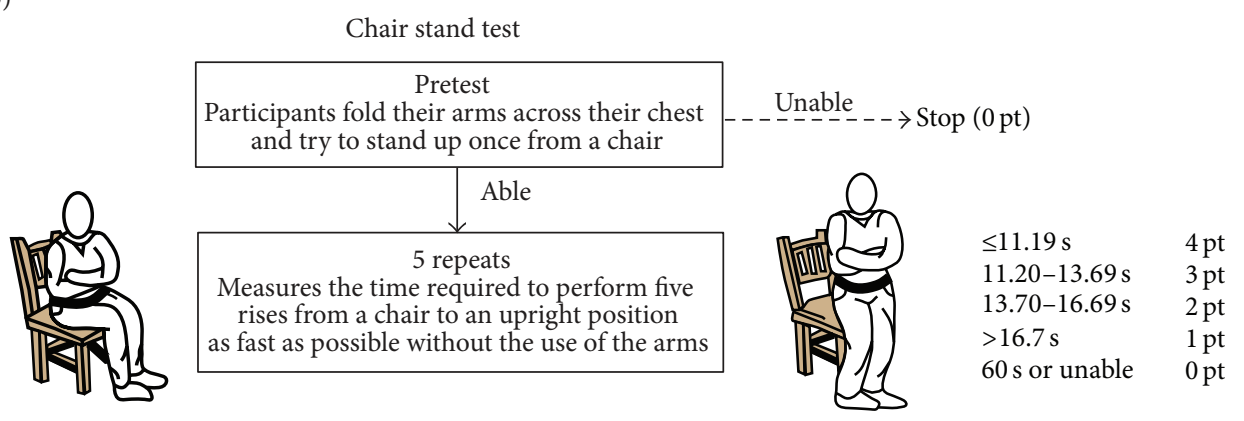

FIGURE 2: Image of the wall chart for the short physical performance battery assessing lower extremity function [21].

influence of predictor variables on the SPPB score, the outcome variable. This allowed us to model the influence of the demographic, anthropometric, and nutritional status variables on physical performance. Other types of regression (all effects and backward) were not applicable due to failure to meet the minimum tolerance level of 0.001 , resulting in an ill-conditioned covariance matrix. Prior to the regression analysis the correlations between all variables were examined for multicollinearity. All of the fatness variables, for example, are correlated at $r=0.9$ or greater. Body mass index (BMI) was chosen as the fatness variable included in regression models because BMI was available for the largest number of participants. Waist circumference is reported to be the most sensitive risk factor for metabolic disease and ageing in South Asians [50] and we replaced BMI with WC in the regressions but there was no change in outcomes. Separate regression models were calculated for mothers and daughters. Statistical significance was set $a$ priori at $P<0.05$.

\section{Results}

6.1. Demographic Characteristics. There was no difference in mean age between UK and BD mothers, but BD residing daughters were younger than UK residing daughters (Table 1). Because of the range in ages for both mothers and daughters, age was entered as a covariate in all regression models. All mothers were married or widowed and according to their demographic history had completed fertility (defined as age over 45 years and at least 5 years since last birth). Mothers in both countries had, on average, an equal number of pregnancies, number of live born children, pregnancy loss, and relatively high fertility. Age at marriage and all fertility 
TABLE 1: Characteristics of the participants given as mean values (standard deviations) or percentages. All values are as measured with no statistical adjustment for age differences.

\begin{tabular}{|c|c|c|c|c|}
\hline & $\begin{array}{l}\text { Cardiff mothers } \\
\qquad(n=40)^{+}\end{array}$ & $\begin{array}{c}\text { Bangladesh } \\
\text { mothers }(n=22)\end{array}$ & $\begin{array}{l}\text { Cardiff daughters } \\
\quad(n=37)^{++}\end{array}$ & $\begin{array}{c}\text { Bangladesh } \\
\text { daughters }(n=22)\end{array}$ \\
\hline Age (yr) & $\begin{array}{c}55.3(8.1) \\
\text { Range = 40-69 }\end{array}$ & $\begin{array}{c}51.9(8.8) \\
\text { Range }=40-70\end{array}$ & $\begin{array}{c}27.4(5.5)^{* *} \\
\text { Range }=17-36\end{array}$ & $\begin{array}{c}22.8(5.1)^{* *} \\
\text { Range }=17-35\end{array}$ \\
\hline Age when married (yr) & $16.3(2.7)$ & $16.5(3.3)$ & $\begin{array}{c}18.7(2.3) \\
n=24\end{array}$ & - \\
\hline Age at 1st birth & $20.8(4.2)$ & $23.2(5.5)$ & $\begin{array}{l}21.3(2.2) \\
N=20\end{array}$ & $\begin{array}{c}20.5(2.6) \\
\quad N=6\end{array}$ \\
\hline Age at final birth & $34.4(6.7)$ & $35.8(5.3)$ & - & - \\
\hline Total pregnancies & $6.6(2.0)$ & $5.6(2.1)$ & $\begin{array}{l}2.9(1.0) \\
N=20\end{array}$ & $\begin{array}{c}2.9(2.3) \\
N=7\end{array}$ \\
\hline Number of living children & $5.6(1.8)$ & $4.9(1.6)$ & $\begin{array}{c}2.6(0.9) \\
N=20\end{array}$ & $\begin{array}{c}2.7(1.5) \\
N=7\end{array}$ \\
\hline Height $(\mathrm{cm})$ & $147.7(6.2)$ & $148.8(5.7)$ & $153.2(5.8)$ & $152.7(6.0)$ \\
\hline Sitting height $(\mathrm{cm})$ & $77.4(3.7)$ & $76.4(3.4)$ & $81.4(2.4)^{* *}$ & $78.2(3.0)^{* *}$ \\
\hline Knee height $(\mathrm{cm})$ & $45.9(2.4)$ & $46.9(2.4)$ & $46.7(2.5)$ & $48.2(2.3)$ \\
\hline Weight (kg) & $66.0(13.4)^{*}$ & $53.5(15.2)^{*}$ & $64.5(14.5)^{* *}$ & $50.8(10.6)^{* *}$ \\
\hline Waist circumference $(\mathrm{cm})$ & $97.9(9.6)^{*}$ & $82.5(14.0)^{*}$ & $82.4(13.0)^{* *}$ & $72.4(8.3)^{* *}$ \\
\hline BMI $\left(\mathrm{kg} / \mathrm{m}^{2}\right)$ & $30.1(5.2)^{*}$ & $24.1(6.4)^{*}$ & $27.5(5.7)^{* *}$ & $21.8(4.4)^{* *}$ \\
\hline \multicolumn{5}{|l|}{ BMI category } \\
\hline Underweight & $0 \%$ & $13.6 \%$ & $0 \%$ & $22.7 \%$ \\
\hline Acceptable risk & $5 \%$ & $40.9 \%$ & $25.0 \%$ & $40.9 \%$ \\
\hline Increased risk & $30 \%$ & $18.2 \%$ & $22.5 \%$ & $22.7 \%$ \\
\hline High risk & $65 \%$ & $27.3 \%$ & $42.5 \%$ & $13.6 \%$ \\
\hline Physical function score ${ }^{\beta}$ & $6.3(3.0)^{*}$ & $9.4(1.9)^{*}$ & $10.8(1.1)$ & $11.2(0.8)$ \\
\hline
\end{tabular}

${ }^{+}$Mean age at migration $=30$ years.

${ }^{++} 20$ born in UK and 17 born in Bangladesh; mean age at migration $=8.2$ years, median $=8.0$, range $=<1$ year to 23 years.

"WHO BMI cut-off categories for South Asians: underweight <18.5; increasing but acceptable risk 18.5-23; increased risk 23.1-27.5; high risk >27.5.

${ }^{\beta}$ Score on the short physical function battery, maximum score $=12$.

${ }^{*}$ Means for the mothers are significantly different, $P \leq .01$.

${ }^{* *}$ Means for the daughters are significantly different, $P \leq .01$.

data of the daughters are incomplete estimates, as 24 of 37 UK-living daughters were married or divorced and only 7 of $22 \mathrm{BD}$-living daughters were married at the time of data collection. The lower number of married daughters in $\mathrm{BD}$ reflects their younger age and our decision to interview the BD-living women in the mother's home-married daughters would be living with their spouse and parents-in-law. No value for "age at final birth" is given for daughters.

6.2. Anthropometry and Nutritional Status. All women were of short stature with a global mean of $150.5 \mathrm{~cm}(\mathrm{sd}=6.4)$. Daughters were, on average, taller and had greater knee height than their mothers, but the differences were not statistically significant (Table 1, Figure 2). Only $2 \%$ of the total UK-BD population lives in Wales so our sample may not be representative of the general UK Bangladeshi population. "Representativeness" was assessed using the secondary data for height, weight, and BMI collected by the Health Survey for England (HSE) 2004, which sampled the larger Bangladeshi community in many regions of England. The HSE 2004 was designed to specifically oversample ethnic minorities. The comparison of the HSE and MINA findings are given in Table 2. MINA mothers and daughters were significantly shorter and had significantly greater BMI than the general UK-BD population. MINA mothers were significantly older than BD women measured for the HSE 2004.

Daughters were divided into three groups: (1) born and living in the UK (UK-UK), (2) living in the UK and born in $\mathrm{BD}$ (UK-BD), and (3) born and living in $\mathrm{BD}$ (BD-BD). UK$\mathrm{BD}$ daughters had an average age at migration of 8.2 years ( $\mathrm{sd}$ $=6.8$ ). At the time of migration 12 were $<11$ years old, 4 were 11-20 years old, and 1 was 23 years old. The three groups of daughters were compared by analysis of variance (ANOVA, Table 3) for each size variable. Significant differences between the three daughter groups were found for sitting height and knee height. Post hoc comparisons found that the BD-BD daughters have smaller sitting height than both UK-UK and UK-BD daughters. UK-BD daughters have lower knee height than UK-UK and BD-BD daughters (Figure 3). As there are no significant differences in total height, these findings mean that $\mathrm{BD}-\mathrm{BD}$ daughters have relatively longer legs for their total height and UK-BD daughters have relatively shorter legs for their total height. While not statistically significant in the ANOVA, UK-UK daughters are, on average, $3.8 \mathrm{~cm}$ taller 
TABLE 2: Comparison of project MINA sample of Bangladeshi mothers and daughters with Bangladeshi women in the same age groups as surveyed in Health Survey for England (HSE) 2004. Values for height, weight, and BMI are the mean \pm standard deviation. Sample size in HSE 2004 varied depending on measurement made. The range of sample size values is given in the table, but $t$-tests were calculated with exact sample sizes.

\begin{tabular}{lccccc}
\hline & MINA UK daughters & HSE 2004 & $P$ value $^{\dagger}$ & MINA UK mothers & HSE 2004 $P$ value \\
\hline Age range (years) & $17-36$ & $17-35$ & & $40-70$ & $40-70$ \\
Sample size & 37 & $228-304$ & & 40 & $84-116$ \\
Mean age (years) & $27 \pm 5.5$ & $26 \pm 5.3$ & NS & $55 \pm 8.1$ & $52 \pm 8.3$ \\
Height (cm) & $153 \pm 5.8$ & $156 \pm 6.2$ & .02 & $148 \pm 6.2$ & 0.03 \\
Weight (kg) & $64 \pm 14.5$ & $61 \pm 12.3$ & NS & $66 \pm 13.4$ & $63 \pm 11.0$ \\
BMI & $27 \pm 5.7$ & $25 \pm 5.2$ & .02 & $30 \pm 5.2$ & $28 \pm 4.3$ \\
\hline
\end{tabular}

${ }^{\dagger} t$-test for MINA sample versus HSE sample in same age group, values for only statistically significant results at $P<0.05$, NS: not significant.

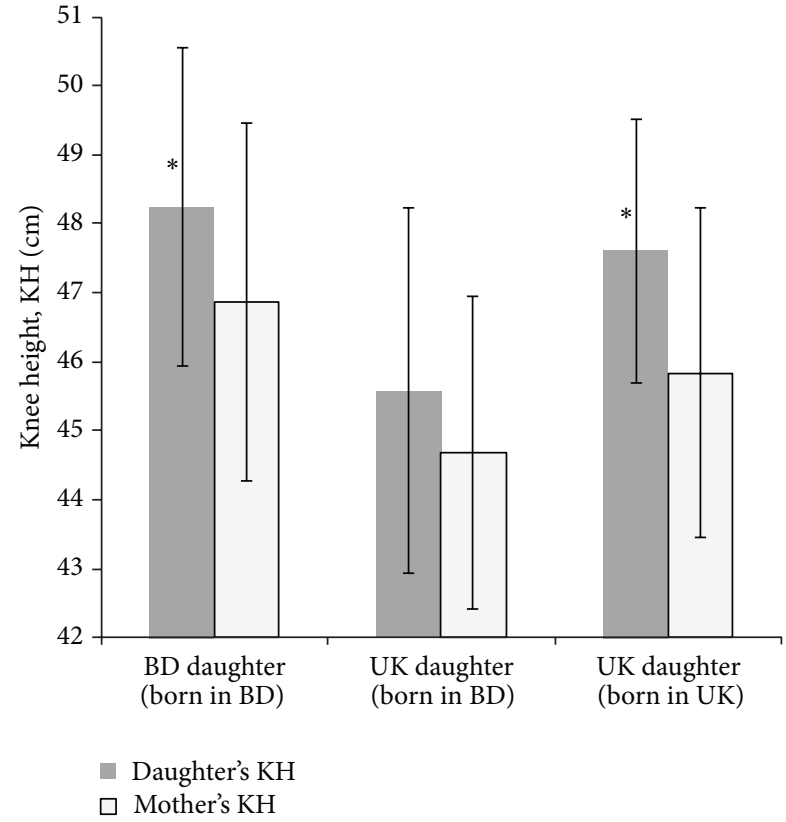

FIgURE 3: Knee height $(\mathrm{KH})$ of daughters and mothers. The asterisks $(*)$ indicate that the only statistically significant differences are between UK-living daughters born in Bangladesh and both Bangladesh-living daughters and UK-living daughters born in the $\mathrm{UK}(P=0.01)$.

than UK-BD daughters. This mean difference is significant in a $t$-test $(t=-2.09, P=0.04)$. Knee height accounts for $2.0 \mathrm{~cm}(53 \%)$ of total height difference. In terms of the biology of human growth and body proportions, the differences in average height, sitting height, and knee height are relatively large and important $[30,51,52]$.

UK-residing women had higher prevalence of overweight and obesity than BD-residing women as indicated by body weight, WC, and BMI (Table 1). Based on internationally recognized cut-off values of BMI for South Asian women, the UK mothers were especially overweight $[50,53]$. Conversely, about one-fifth of the BD sample of women was underweight.

6.3. Physical Function Test Scores. Results from SPPB indicate that total physical function score tends to be progressively
TABLE 3: Means (+/-sd) for height, sitting height, and knee height (all measured as $\mathrm{cm}$ ) of daughters born and living in Bangladesh (BD-BD, $n=22$ ), UK living daughters born in Bangladesh (UK$\mathrm{BD}, n=17$ ), or in the UK (UK-UK, $n=20$ ). The three groups of daughters were compared by analysis of variance (ANOVA) for each size variable. $F$ and $P$ values from the ANOVA are given in the table. For the significant ANOVA results, post hoc comparisons are given below the table.

\begin{tabular}{lccccc}
\hline & BD-BD & UK-UK & UK-BD & $F$ & $P$ \\
\hline Height & $152.7(6.0)$ & $154.8(5.0)$ & $151.0(6.2)$ & 2.86 & NS \\
Sitting height & $78.2(3.0)$ & $81.7(2.4)$ & $80.9(2.3)$ & 10.7 & $<0.00$ \\
Knee height & $48.2(2.3)$ & $47.6(1.9)$ & $45.6(2.7)$ & 6.81 & $<0.00$ \\
\hline
\end{tabular}

Significant post hoc contrasts.

Sitting height: UK-UK $>$ BD-BD $P<0.00$; UK-BD $>$ BD-BD $P<0.00$.

Knee height: UK-UK $>$ UK-BD $P=0.01$; $\mathrm{BD}-\mathrm{BD}>\mathrm{UK}-\mathrm{BD}>P<0.00$.

lower as the age of the participants increases. This trend is strongest for the mothers living in the UK but is evident for mothers living in $\mathrm{BD}$ and for daughters in both the UK and BD (Figure 4). All participants attempted each task of the test. BD mothers had significantly higher scores than UK mothers. The average total score for the UK mothers falls below the test's cut-off value for older women of 7 , indicating poor physical performance. Indeed, 21 individuals (53\% of our sample) scored $<7,6$ were at or below a score of 2 , and 2 women scored 0 as they were unable to perform any elements of the test.

The BD daughters tended to score higher on the SPPB than the UK daughters. The SPPB has no validated cut-off value for poor physical performance for people under the age of 65 years $[49,54,55]$. When the SPPB is applied to younger and healthier populations, every participant without impairment is expected to achieve the maximum score of 12 . We conferred with Professor Jack M. Guralnik, the creator of the SPPB, to review the MINA data for the SPPB. He kindly did so and suggested that we propose a cutoff of 11 points to identify the UK and BD daughters with evidence of risk for future disability and, possibly, current health impairment and functional limitations. This is, of course, exploratory and a hypothesis needs to be tested by longitudinal studies. Statistically, a cutoff of 11 points is meaningful, as a $t$-test for the difference between a SPPB score of 12 versus 11 with sd $=1$ and $n=10$ per group is significant at $P=0.04$. Eleven 


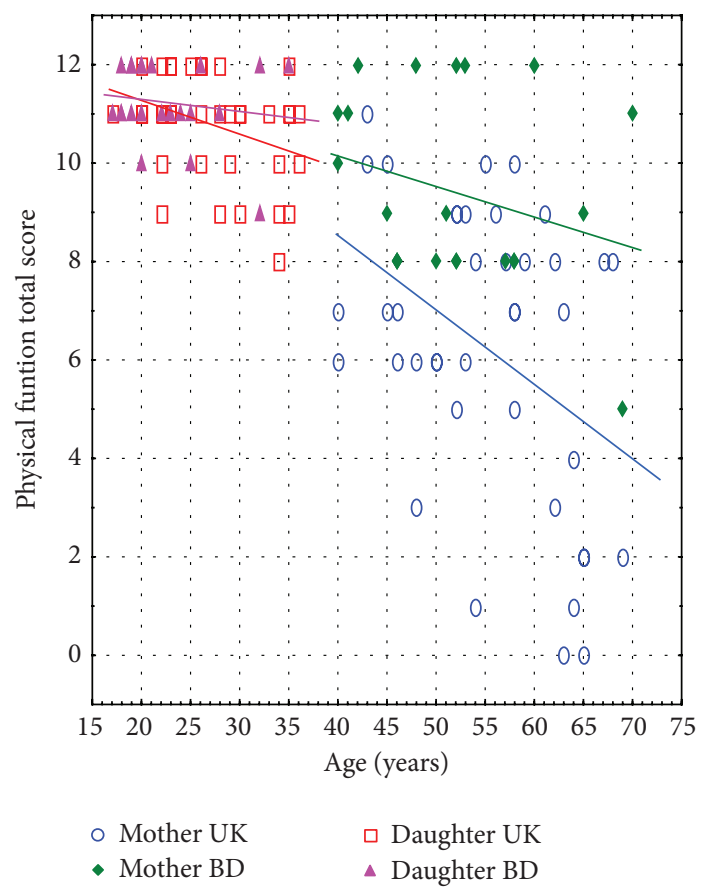

FIgURE 4: Total score (unadjusted) of the Guralnik short physical performance battery for each participant by age. For the "mothers" a score $<7$ indicates a low level of physical performance for the lower limbs. For the daughters it is suggested that a score $<11$ indicates low physical performance. Linear regression is used to fit the distribution of scores for each subgroup (mother UK, mother BD, etc.). These regression lines represent between-individual change and not aging. Colour version appears online.

of the UK daughters scored $<11$ points, which is significantly below the expected score of 12 points $(P=0.009)$. Only 3 of the $\mathrm{BD}$ daughters scored $<11$ points, which is not statistically lower than expected. More important, possibly, is that of the UK-living daughters; 8 UK-BD daughters scored $<11$ points compared with only 3 UK-UK daughters, which is a statistically significant difference (proportions test, $P=$ $0.008)$.

Results of the comparisons between subtests of the SPPB are given in Table 4 . The results indicate that the BD mothers score significantly higher than the UK mothers on each component of the test, as well as for the total final score. The BD daughters score significantly higher than the UK daughters for only the 4 meter walking speed component.

6.4. Knee Height, Fertility, and Physical Function. Results of the forward stepwise multiple regression analyses for predictors of the SPPB score are shown in Table 5. The model for the mothers included the predictor variables current age, age at first birth, height, knee height, and BMI. The model for the daughters included the predictor variables current age, migrant (no $=0$, yes $=1$ ), height, knee height, BMI, mother's height, mother's knee height, mother's age at first birth, and daughter's birth order. Any participant missing any of these variables was excluded from the analysis and this resulted in sample sizes of 61 mothers $(1$ missing) and 58
TABle 4: Mean scores (and standard errors, s.e.) for the three subtests and total score of the short physical performance battery of lower body function for mothers and daughters residing in the UK or $\mathrm{BD}$. The difference between the means is assessed by analysis of variance. Scores are unadjusted for the influence of other variables.

\begin{tabular}{lcccc}
\hline Mothers & $\begin{array}{c}\text { BD }(n=22) \\
\text { Mean (s.e) }\end{array}$ & $\begin{array}{c}\text { UK }(n=40) \\
\text { Mean (s.e) }\end{array}$ & $F$ & $P$ \\
\hline Balance & $3.8(0.2)$ & $3.0(0.1)$ & 5.36 & 0.02 \\
4 m walk & $3.5(0.2)$ & $1.9(0.1)$ & 40.22 & 0.00 \\
Chair rise & $2.1(0.2)$ & $1.4(0.2)$ & 6.29 & 0.01 \\
Final score & $9.0(0.4)$ & $6.0(0.3)$ & 19.55 & 0.00 \\
\hline Daughters & $\mathrm{BD}(n=22)$ & $\mathrm{UK}(n=37)$ & & \\
\hline Balance & $4.0(0.2)$ & $4.0(0.2)$ & 0.59 & NS \\
4 m walk & $4.0(0.2)$ & $3.6(0.1)$ & 7.84 & 0.01 \\
Chair rise & $3.2(0.2)$ & $3.2(0.2)$ & 0.22 & NS \\
Final score & $11.2(0.2)$ & $10.8(0.1)$ & 2.76 & NS \\
\hline
\end{tabular}

daughters (1 missing). The missing case is due to a mother in Cardiff without a reported or estimated "age at first birth." Total height was entered into all models to standardize $\mathrm{KH}$ for height, as taller women tend to have greater knee height. We were interested in the influence of both absolute $\mathrm{KH}$ and $\mathrm{KH}$ relative to total stature. Birth order was entered into the daughters' regression model as a control for the tendency for later born offspring to be shorter in height than earlier born offspring [56].

Reported in Table 5 are the predictor variables that remained in the model after the forward step-building process. The "country of residence" at the time of measurement for participants was included as a predictor variable (either UK or BD) in the initial model building process. With "country of residence" included in the models, this variable was the only significant predictor of SPPB score for both mothers and daughters. "Country of residence" is correlated significantly with SPPB score $(r=0.32)$, BMI $(r=-0.46)$, and knee height $(r=0.26)$. Individually, correlations of these values would not be expected to result in multicollinearity, but combined in the regression model their interaction is sufficient so that the "country of residence" variable dominates the mathematics of the regression model. We decided not to include "country of residence" in the final regression models reported here. In part, this decision was based on our hypotheses which focus on knee height and mother's fertility. Moreover, "country of residence" confounds the daughters' regression model, as our sample includes migrants to the UK and UK-born participants. Labelling them all as "UK residents" fails to take into account this important difference. Accordingly, the daughters' model included a "migrant" variable to account for country of birth.

For the mothers (Table 5(a)), greater $\mathrm{KH}$ is most strongly predictive of a higher SPPB score. Older current age is next strongly predictive of a lower SPPB score. Greater BMI is associated with a lower SPPB score, but not statistically significant $(P=0.06)$. Age at first reproduction has no significant association with SPPB score and was eliminated from the final reported model. Taken together, these variables 
TABle 5: Significant predictors of total score for the Short Physical Performance Battery (SPPB). Statistical significance of the hypothesized predictors was assessed by forward stepwise multiple regression. (a) Model for the mothers; variables entered into the regression are current age, age at first birth, height, knee height and BMI. (b) Model for the daughters; variables entered into the regression are current age, migrant (no $=0$, yes $=1$ ), height, knee height, BMI, mother's height, mother's knee height, mother's age at first birth, and daughter's birth order. The predictors shown in the tables are those that survived the forward stepwise regression process. The relative importance of each predictor is indicated by the absolute value of its standardized beta. For the mothers the variables "knee height" and "current age" are the best predictors of SPPB score. Greater knee height increases and older age decreases the score. For the daughters the variables "migrant" and "current age" are the best predictors of SPPB score. Being born in Bangladesh and then migration to the UK and older age both decrease the score.

(a) Mothers

\begin{tabular}{lcccccc}
\hline & Standardized beta & SE & Beta & SE & $t(56)$ & $P$ \\
\hline Intercept & & & 8.11 & 8.87 & 0.91 & 0.36 \\
Current age & -0.43 & 0.12 & -0.15 & 0.04 & -3.70 & 0.00 \\
Knee height & 0.49 & 0.19 & 0.60 & 0.23 & 2.61 & 0.01 \\
BMI & -0.22 & 0.11 & -0.11 & 0.06 & -1.92 & 0.06 \\
Height & -0.23 & 0.19 & -0.12 & 0.09 & -1.22 & 0.23 \\
\hline
\end{tabular}

$N=61, R=0.58, R^{2}=0.34$, adjusted $R^{2}=0.29, F(4,56)=7.12, P=0.0001$.

(b) Daughters

\begin{tabular}{lcccccc}
\hline & Standardized beta & SE & Beta & SE & $t(53)$ & $P$ \\
\hline Intercept & & & 4.54 & 6.83 & 0.66 & 0.51 \\
Migrant & -0.41 & 0.11 & -2.58 & 0.70 & -3.69 & $<0.01$ \\
Current age & -0.31 & 0.11 & -0.12 & 0.04 & -2.96 & $<0.01$ \\
Knee height & 0.19 & 0.11 & 0.24 & 0.13 & 1.77 & 0.08 \\
\hline
\end{tabular}

$N=58, R=0.65, R^{2}=0.43$, adjusted $R^{2}=0.40, F(3,54)=13.43, P<0.0001$.

account for $29 \%$ of the variance in the SPPB score for the mothers (the adjusted $R^{2}$ ).

The regression analysis for the daughters indicates that migration from $\mathrm{BD}$ versus birth in the UK was a significant predictor of SPPB scores (Table 5(b)). The UK-BD daughters had a lower SPPB score than UK-UK and BD-BD daughters. Older age is predictive of a lower physical function score. Greater $\mathrm{KH}$ is associated with a higher score, but not statistically significant $(P=0.08)$. It is noteworthy that the significant migration effect is independent of the KH effect. None of the intergenerational variables (mother's height, mother's knee height, age of mother at first birth, or daughter's birth order) were significant and were eliminated from the final reported model. The regression model for daughters accounts for $40 \%$ of the variance (adjusted $R^{2}$ ) in physical function score.

\section{Discussion}

Project MINA offers a novel perspective on childhood nutrition and health, migration, and physical function in older age and young adult Bangladeshi mothers and daughters. Few, if any, other studies compare two groups of the same ethnicity in terms of two generations and two locations-the home country and the "Diaspora." To our knowledge this is the first time that data collected using the Short Physical Performance Battery has been published for Bangladeshis.

7.1. Childhood Health, Nutrition, and Knee Height. In this paper we employ a life course hypothesis and an intergenerational influences hypothesis and estimate early life conditions for both generations of women using the measurement of knee height $(\mathrm{KH})$. As reviewed above, it is known that in adverse environments total stature is reduced, with legs more affected than the upper body and the tibia more compromised than the femur. Conversely, it is also known that in better environments stature tends to increase, and the tibia elongates more than the femur $[57,58]$.

7.2. Tests of Our Hypotheses. The physical functions evaluated by the SPPB have clinical validity to characterize older persons across a broad spectrum of lower extremity function [49]. It has been shown in studies in Europe, North America, and Brazil that SPPB scores may be used to predict "...future disability, hospitalization, and death even in participants who report no disability at initial testing" [21]. From this perspective, scores on the SPPB are broadly reflective of overall current health. It is important to note that the determinants of physical function are complex, with several interactions between mechanical, biological, and sociocultural variables. We discuss some of these influences below.

Based on our conceptual model, the findings from the test of our knee height hypothesis may be interpreted to indicate that girls who suffered poorer nutrition and health between birth and puberty had reduced knee height and grew up to be women with lower physical function. The knee height-physical performance relationship is statistically significant for the mothers, but not so for the daughters $(P=$ 0.08). Overall, our findings provide additional support for the use of adult $\mathrm{KH}$ as a biomarker of health and accrued reserve capacity during the first decade after birth. Adult $\mathrm{KH}$ may also serve as a biomarker of current adult health and future health risk. To our knowledge this is the first such demonstration of these health applications for knee height for Bangladeshis. Our findings for an effect of early life environmental conditions on physical function in adult life complement related research which found that childhood socioeconomic status was associated with $\mathrm{SPPB}$ a half century later [59]. The participants in that study were from the British 1946 birth cohort and were evaluated at the age of 53 years. Their parents' socioeconomic status was used as a proxy for the quality of their early life environment. Higher occupation status of their fathers and greater educational level of their mothers predicted significantly higher SPPB scores.

7.3. Why Do the UK-BD Daughters Have the Shortest Knee Height? The UK provides, in general, a healthier environment for infant and child growth than does $\mathrm{BD}$, so greater $\mathrm{KH}$ for all UK-living daughters compared with their mothers might be expected. The UK-BD daughters, however, have shorter $\mathrm{KH}$ than the UK-UK and the BD-BD daughters. This 
is unlikely due to a genetic difference, as these daughters are from the same general population. Furthermore, we compared mothers and daughters of the two UK-living groups and found that for UK-BD daughters only $53 \%$ of their mothers had a shorter $\mathrm{KH}$ than the daughter. In contrast, $80 \%$ of mothers of the UK-UK daughters have a shorter $\mathrm{KH}$ than their daughter. This is a significant difference $(P=0.04)$. Given the sensitivity of $\mathrm{KH}$ to the environment for early life growth, this difference indicates that something about the prepubertal environment for physical growth and building reserve capacity was better for the UK-UK daughters.

The difference in $\mathrm{KH}$ between UK-UK and UK-BD daughters may be due to the relatively harsh environment for growth in $\mathrm{BD}$ before the UK-BD daughters migrated to the UK (mean age at migration was 8.2 years old). Reviews of research from the 20th century report that people of all social classes in Sylhet had relatively high levels of infectious disease exposure, including intestinal parasites, compared with the UK. Virtually all residents of Sylhet were also exposed to an environment with unsanitary sewage and waste disposal systems and limited drinking water treatment capacity [6064]. Today, Sylhet Division, including all urban and rural areas, has the highest neonatal, postneonatal, infant, and under-5 mortality prevalence of all Bangladesh, estimated to be 59 deaths per 1,000 live births [65]. These are all indicators of poor living conditions, which were likely to have been even worse in the past when the BD-born participants of the MINA project were growing up.

Bangladeshi women living in the UK tend to be from wealthier families in the Sylhet Division [64]. Even so, a 2007 report by the United Nations Population Fund indicates that the infant mortality rate for the wealthiest and most highly educated groups within urban Bangladesh were between 49 and 58/1,000 live births [66]. Infant mortality is a sensitive indicator of the health environment and high infant mortality rates predict poor body growth of the surviving population $[56,67]$. In contrast to the data from Bangladesh, the postneonatal mortality rate was 6.9/1,000 live births for infants born to Bangladeshi mothers living in East London between the years 1987 and 1990.

The health environment differences between UK-UK and UK-BD daughters during their prepubertal years may not be the only important influence on their KH. Finch [15, page 17] proposes expanding the concepts of life course development and intergenerational influences, "...to include three groups of factors: nutritional deficits, chronic stress from socio-economic factors, and direct and indirect damage from infections." If we accept this broadened definition, then it is also possible that some stress factors or factors associated with migration from $\mathrm{BD}$ to the UK-before, during, and after-account for some of the difference in both $\mathrm{KH}$ and SPPB scores between the UK-BD and UKUK daughters. Our preliminary analysis of the migration history questionnaires and the interviews conducted with the participants indicate several types of social stress related to migration. These stresses include family separation, for example, fathers migrating first and leaving their wives and children in Bangladesh, financial insecurity due to a lack of remittances from the UK to families left in Bangladesh, lack of employment by adults after migrating to the $\mathrm{UK}$, and limited social support due to language barriers. These stressors may have had a negative effect on physical growth and may have reduced reserve capacity, but the data require further formal analysis before we can establish any relationships. It is important to emphasize that the significant effect for "migration" as a predictor of the SPPB score for the daughters (Table 5(b)) is independent from the nonstatistically significant, but biologically detectable, association of daughter's $\mathrm{KH}$ with SPPB score. Based on the standard errors reported in Table 5(b), a larger sample size would likely result in a statistically significant effect for $\mathrm{KH}$ of the daughters on their SPPB scores.

7.4. Fertility, Intergenerational Influences, and Physical Function. Our hypotheses of a relationship between age at first reproduction and intergenerational influences with physical function were not supported. This may mean that there is no effect, that our sample size is not adequate to detect an effect, or that some unmeasured characteristics of the mothers interact with and mask the effect of age at first birth. Previous research finds positive, negative, and neutral effects between age at first birth and other fertility variables with later life health [68-71]. In a review of this research, Jasienska [38] suggested that studies are needed for the total energy budget of women, including tradeoffs with disease, socioeconomic status, and the costs of investment in one's own offspring as well as the children of others (e.g., nieces, nephews, and adoptions) and grandchildren throughout their life. Such studies may also lead to better understanding of intergenerational effects on the variation between individual women in their reserve capacity, their reproductive history, and their health in later life.

7.5. Physical Function, Age, and Sociocultural Lifestyle. In our sample, SPPB scores tended to decline as the age of the participants increased. For this cross-sectional sample, such declines could be the result of cohort or period effects and not the direct result of greater age per se. UK-living mothers had lower scores on all of the components of the SPPB compared with BD-living mothers. UK-living daughters had lower scores only on walking speed compared with BD-living daughters.

One important influence on walking speed is leg length, as longer leg length generally results in faster speed [72]. BD$\mathrm{BD}$ and UK-UK daughters have, on average, greater knee height, and longer legs in total, than the UK-BD daughters (leg length may be estimated as height minus sitting height, using the data in Table 1). Another important determinant of the total SPPB score is body fatness. Consistent with other research, the MINA study found that greater fatness (BMI) tends to be associated with a lower score-not statistically significant in our regression model but statistically significant in Pearson correlation (BMI: SPPB, $r=-0.21, P=0.02$ ). Longitudinal studies find that loss of body fat tends to increase the SPPB score [73]. Due to the cross-sectional design of this study, we are not able to determine whether higher levels of fatness are due to low levels of activity, or vice versa. 
Lifestyles in BD versus UK may also explain some of the differences in physical function and fatness between locations. Interviews and ethnographic observations with our participants indicate that BD-living mothers and daughters, regardless of their socioeconomic status, perform more physical activities including walking outdoors, carrying bundles, taking stairs, and doing housework. Several BDliving families of lower income status had small agricultural holdings and the women tended their fields and livestock. Other women were from relatively wealthy families and had household help to perform many chores. Even so, these wealthier women perform domestic duties while overseeing the work of household staff and carried out social activities that required walking and carrying objects. These types of moderate to vigorous physical activities are recommended to prevent losses in physical function [74, 75]. In Sylhet, women of lower socioeconomic status generally squat to use the bathroom, although those with higher status will use westernstyle toilets similar to UK living women. The difference may strengthen the leg muscles of some of the Bangladesh-living women so that they would do better on chair rise component of the SPPB.

In contrast to the Bangladesh-living women, Bangladeshi women living in the UK have the lowest self-reported levels of physical activity of all ethnic groups [22]. There are several likely reasons for this. One is that Bangladeshi cultural values dictate that daughters and daughters-in-law should provide care for their mothers and mothers-in-law [42]. This cultural value would apply equally in the $\mathrm{UK}$ and $\mathrm{BD}$, but other factors are especially important in the UK. In their systematic review of physical activity among South Asian immigrant women, Babakus and Thompson [23] found that barriers to physical activity (PA) include confusion as to what types and how much PA to perform, that doing PA is perceived as a selfish act, that there is no spare time for PA, that there are no culturally appropriate facilities (to preserve the modesty of Muslim women) and safety concerns for unaccompanied women, that PA would exacerbate existing illnesses, poor weather, and a fatalistic belief that health and illness are Allah's will. An older survey of 149 Bangladeshi parents living in the East Midlands region of the UK [76] reported that these barriers to physical activity were already in place for girls by secondary school age.

Another reason for low physical activity for the Bangladeshi mothers in the UK is that they suffer from social isolation due to poor English language skills, fear of unfamiliar social environments, lack of knowledge of social services, and fear of the cold [41, 42, 77]. A survey of 469 UK ethnic minority elders aged 65+ living in the community provided prevalence estimates for social isolation [78]. It was found that $40 \%$ of the Bangladeshis interviewed report "often" feeling lonely in contrast with the norm of $8-10 \%$ for white British respondents. "Loneliness is important because it is associated with a range of negative outcomes including low levels of physical activity, poor physical and mental health, elevated mortality, and increased use of services" [78, page 78].

The high levels of fatness found for UK-living women may also be, in part, due to a cultural value. Some Bangladeshi women appear to regard "plumpness" as a sign of good health, greater wealth, and higher social status [79]. Biomedical research with South Asians in their homelands and in Europe finds that "plumpness" is a risk factor for poor health, as there is a nearly monotonic increase in the incidence of type 2 diabetes and its comorbidities with greater waist circumference [50]. As is the case for other medical conditions, cultural values and biomedical understanding may be at odds, which can hamper health care delivery and patient compliance [80].

Culturally tailored interventions, such as exercise/dance classes appropriate for $\mathrm{BD}$ women, may help alleviate both the lack of physical activity and loneliness. Appropriate interventions to increase physical activity may also improve physical function and reduce health risks. The MINA project provided "Extend" light exercise and "Bollywood-style" dance sessions at the data collection events, with virtually all Bangladeshi mothers and daughters participating. These activities at the data collection sessions were highlighted by participants as a positive aspect of their involvement with MINA.

7.6. Limitations and Strengths. Limitations of this study include (1) lack of the ability to determine cause and effect due to the cross-sectional design of the study; (2) small sample size in relation to the total population of Bangladeshis; (3) possible selective exclusions of the more disabled; and (4) selective mortality resulting in a Bangladeshi older population that was more highly functional.

Strengths of the study include (1) the recruitment of samples in both the UK and BD that are considered "hard to reach" and at high risk for chronic diseases and early ageing; (2) the application of a participatory framework that included the community at all stages, which was instrumental in meeting recruitment targets and ensuring that the study design and all data collection methods, tools, and approaches were culturally appropriate and the results were interpreted by culturally and linguistically compatible researchers; (3) training community researchers which builds capacity within their communities; (4) standardised anthropometric and SPPB measurements being conducted by the same highly trained individual (JT) for all participants in both locations; (5) all of the participants in our sample agreed to all measurements and interviews, even though two of the UK-living mothers were not physically able to do any of the tasks of the SPPB; and (6) finding lower than expected physical function scores for all UK-living Bangladeshi women, which highlights their risks for poor health, disability, and early mortality.

In conclusion, for these Bangladeshi adult women early life health and nutritional status, captured by knee height, are a predictor of physical function in later life. Age at first birth does not seem to influence the predictive power of knee height. Greater abdominal fat is associated with impaired physical function. International migration is associated with shorter knee height for daughters and with poorer physical function for both generations of Bangladeshi women. These findings demonstrate how early life health and nutritional status influence the quality of both physical growth and health across the life course.

Project MINA lends support to policy and practice to protect and enhance health in early life in order to forestall 
disability and illness in later life. The "Flying Start" programme initiated by the Welsh Government in 2012 provides services to families with children under 4 years of age to enhance physical and cognitive development [81]. Such programmes may save national health systems considerable expense and enrich the personal lives of younger and older people and their families.

\section{Conflict of Interests}

The authors declare that there is no conflict of interests regarding the publication of this paper.

\section{Acknowledgments}

The authors would like to acknowledge all participants who volunteered for this study, the community researchers who assisted with recruitment, data collection, and analyses (Fateha Ahmed, Nabila Ahmed, Jusna Begum, Rajma Begum, Runa Begum, Shelina Hurt, Sofina Khatun, Farida KhatunMiah, Rehana Miah, Shaheena Nahar Omar), and the community stakeholders and leaders who shared their views and insights with the MINA research team. The authors thank Dr. Jack Guralnik for his advice. This work was supported by Grant no. RES-354-25-0002 of the Economic and Social Research Council, New Dynamics of Ageing Programme, UK.

\section{References}

[1] E. M. Crimmins and C. E. Finch, "Infection, inflammation, height, and longevity," Proceedings of the National Academy of Sciences of the United States of America, vol. 103, no. 2, pp. 498503, 2006.

[2] D. Kuh, R. Hardy, S. Butterworth et al., "Developmental origins of midlife physical performance: evidence from a British birth cohort," American Journal of Epidemiology, vol. 164, no. 2, pp. 110-121, 2006.

[3] D. J. P. Barker, "The origins of the developmental origins theory," Journal of Internal Medicine, vol. 261, no. 5, pp. 412-417, 2007.

[4] T. Bengtsson and G. Broström, "Do conditions in early life affect old-age mortality directly and indirectly? Evidence from 19thcentury rural Sweden," Social Science \& Medicine, vol. 68, no. 9, pp. 1583-1590, 2009.

[5] K. M. Godfrey, P. D. Gluckman, and M. A. Hanson, "Developmental origins of metabolic disease: life course and intergenerational perspectives," Trends in Endocrinology \& Metabolism, vol. 21, no. 4, pp. 199-205, 2010.

[6] H. Beltrán-Sánchez, E. M. Crimmins, and C. E. Finch, "Early cohort mortality predicts the rate of aging in the cohort: a historical analysis," Journal of Developmental Origins of Health and Disease, vol. 3, pp. 380-386, 2012.

[7] I. Emanuel, "Maternal health during childhood and later reproductive performance," Annals of the New York Academy of Sciences, vol. 477, pp. 27-39, 1986.

[8] I. Emanuel, C. Kimpo, and V. Moceri, "The association of grandmaternal and maternal factors with maternal adult stature," International Journal of Epidemiology, vol. 33, pp. 1243-1248, 2004.
[9] M. I. Varela-Silva, A. R. Frisancho, B. Bogin et al., "Behavioral, environmental, metabolic and intergenerational components of early life undernutrition leading to later obesity in developing nations and in minority groups in the USA," Collegium Antropologicum, vol. 31, no. 1, pp. 39-46, 2007.

[10] A. J. Drake and B. R. Walker, “The intergenerational effects of fetal programming: non-genomic mechanisms for the inheritance of low birth weight and cardiovascular risk," Journal of Endocrinology, vol. 180, pp. 1-16, 2004.

[11] M. I. Varela-Silva, H. Azcorra, F. Dickinson, B. Bogin, and A. R. Frisancho, "Influence of maternal stature, pregnancy age, and infant birth weight on growth during childhood in Yucatan, Mexico: a test of the intergenerational effects hypothesis," American Journal of Human Biology, vol. 21, no. 5, pp. 657-663, 2009.

[12] M. Hanson, K. M. Godfrey, K. A. Lillycrop, G. C. Burdge, and P. D. Gluckman, "Developmental plasticity and developmental origins of non-communicable disease: theoretical considerations and epigenetic mechanisms," Progress in Biophysics and Molecular Biology, vol. 106, no. 1, pp. 272-280, 2011.

[13] K. Godfrey, K. Lillycrop, G. Burdge, P. Gluckman, and M. Hanson, "Non-imprinted epigenetics in fetal and postnatal development and growth," Nestlé Nutrition Workshop Series, vol. 71, pp. 115-126, 2013.

[14] D. Kuh, "A life course approach to healthy aging, frailty, and capability," The Journals of Gerontology A: Biological Sciences and Medical Sciences, vol. 62, no. 7, pp. 717-721, 2007.

[15] C. E. Finch, "Evolution of the human lifespan: past, present, and future. Phases in the evolution of human life expectancy in relation to the inflammatory load," Proceedings of the American Philosophical Society, vol. 156, no. 1, pp. 9-44, 2012.

[16] J. J. McArdle, E. Ferrer-Caja, F. Hamagami, and R. W. Woodcock, "Comparative longitudinal structural analyses of the growth and decline of multiple intellectual abilities over the life span," Developmental Psychology, vol. 38, no. 1, pp. 115-142, 2002.

[17] H. Kaplan, K. Hill, J. Lancaster, and A. Robson, "Embodied capital and the evolutionary economics of the human lifespan," Population and Development Review, pp. 152-182, 2003.

[18] D. E. Crews, "Senescence, aging, and disease," Journal of Physiological Anthropology, vol. 26, no. 3, pp. 365-372, 2007.

[19] N. J. Spence, "The long-term consequences of childbearing: physical and psychological well-being of mothers in later life," Research on Aging, vol. 30, pp. 722-751, 2008.

[20] B. Bogin, "Childhood, adolescence, and longevity: a multilevel model of the evolution of reserve capacity in human life history," American Journal of Human Biology, vol. 21, no. 4, pp. 567-577, 2009.

[21] J. Guralnik, Assessing Physical Performance in the Older Patient, National Institute on Aging, 2012.

[22] K. Sproston and J. Mindell, Health Survey For England 2004: The Health of Ethnic Minority Groups, 2006.

[23] W. S. Babakus and J. L. Thompson, "Physical activity among South Asian women: a systematic, mixed-methods review," International Journal of Behavioral Nutrition and Physical Activity, vol. 9, pp. 150-169, 2012.

[24] N. M. Peel, S. S. Kuys, and K. Klein, "Gait speed as a measure in geriatric assessment in clinical settings: a systematic review," The Journals of Gerontology A: Biological Sciences and Medical Sciences, vol. 68, no. 1, pp. 39-46, 2013.

[25] J. Maurer, "Height, education and later-life cognition in Latin America and the Caribbean," Economics \& Human Biology, vol. 8, no. 2, pp. 168-176, 2010. 
[26] M. Mceniry and A. Palloni, "Early life exposures and the occurrence and timing of heart disease among the older adult Puerto Rican population," Demography, vol. 47, no. 1, pp. 23-43, 2010.

[27] Z. Zhang, D. Gu, and M. D. Hayward, "Childhood nutritional deprivation and cognitive impairment among older Chinese people," Social Science \& Medicine, vol. 71, no. 5, pp. 941-949, 2010.

[28] M. Prince, D. Acosta, A. D. Dangour et al., "Leg length, skull circumference, and the prevalence of dementia in low and middle income countries: a 10/66 population-based cross sectional survey," International Psychogeriatrics, vol. 23, no. 2, pp. 202-213, 2011.

[29] I. Leitch, "Growth and health," The British journal of nutrition, vol. 5, no. 1, pp. 142-151, 1951.

[30] B. Bogin and M. I. Varela-Silva, "Leg length, body proportion, and health: a review with a note on beauty," International Journal of Environmental Research and Public Health, vol. 7, no. 3, pp. 1047-1075, 2010.

[31] B. Bogin and J. Baker, "Low birth weight does not predict the ontogeny of relative leg length of infants and children: an allometric analysis of the NHANES III sample," American Journal of Physical Anthropology, vol. 148, no. 4, pp. 487-494, 2012.

[32] H. Azcorra, M. I. Varela-Silva, L. Rodriguez, B. Bogin, and F. Dickinson, "Nutritional status of Maya children, their mothers, and their grandmothers residing in the City of Merida, Mexico: revisiting the leg-length hypothesis," American Journal of Human Biology, vol. 25, no. 5, pp. 659-665, 2013.

[33] E. Pomeroy, J. T. Stock, S. Stanojevic, J. J. Miranda, T. J. Cole, and J. C. K. Wells, "Trade-offs in relative limb length among Peruvian children: extending the thrifty phenotype hypothesis to limb proportions," PLoS One, vol. 7, no. 12, Article ID e51795, 2012.

[34] J. W. Prothro and C. A. Rosenbloom, "Physical measurements in an elderly black population: knee height as the dominant indicator of stature," Journal of Gerontology, vol. 48, no. 1, pp. $15-18,1993$.

[35] R. Roubenoff and P. W. Wilson, "Advantage of knee height over height as an index of stature in expression of body composition in adults," The American Journal of Clinical Nutrition, vol. 57, pp. 609-613, 1993.

[36] W. C. Chumlea, S. S. Guo, K. Wholihan, D. Cockram, R. J. Kuczmarski, and C. L. Johnson, "Stature prediction equations for elderly non-Hispanic white, non- Hispanic black, and Mexico-American persons developed from NHANES III data," Journal of the American Dietetic Association, vol. 98, no. 2, pp. 137-142, 1998.

[37] J. Mirowsky, "Age at first birth, health, and mortality," Journal of Health and Social Behavior, vol. 46, no. 1, pp. 32-50, 2005.

[38] G. Jasienska, "Reproduction and lifespan: trade-offs, overall energy budgets, intergenerational costs, and costs neglected by research," American Journal of Human Biology, vol. 21, no. 4, pp. 524-532, 2009.

[39] K. L. Kramer, "Application of an integrated cooperation approach to human cooperative breeders," Behavioural Processes, vol. 76, no. 2, pp. 167-169, 2007.

[40] C. W. Kuzawa and E. A. Quinn, "Developmental origins of adult function and health: evolutionary hypotheses," Annual Review of Anthropology, vol. 38, pp. 131-147, 2009.

[41] B. Gray, "Social exclusion, poverty, health and social care in tower hamlets: the perspectives of families on the impact of the family support service," British Journal of Social Work, vol. 33, no. 3, pp. 361-380, 2003.

[42] J. Merrell, F. Kinsella, F. Murphy, S. Philpin, and A. Ali, "Support needs of carers of dependent adults from a Bangladeshi community," Journal of Advanced Nursing, vol. 51, no. 6, pp. 549-557, 2005.

[43] ONS, 2012, 2011 Census, United Kingdom, http://www.ons .gov.uk/ons/guide-method/census/2011/index.html.

[44] C. Alexander, S. Firoz, and N. Rashid, The Bengali Diaspora in Britain: A Review of the literature, London, UK, 2010.

[45] K. Gardner, Age, Narrative and Migration: the Life Course and Life Histories of Bengali Elders in London, Heidelberg, Germany, 2002.

[46] C. Phillipson, N. Ahmed, and J. Latimer, Women in Transition. A Study of the Experiences of Bangladeshi Women Living in Tower Hamlets, The Policy Press, Bristol, UK, 2003.

[47] B. Bogin and M. I. Varela-Silva, "Fatness biases the use of estimated leg length as an epidemiological marker for adults in the NHANES III sample," International Journal of Epidemiology, vol. 37, no. 1, pp. 201-209, 2008.

[48] J. M. Guralnik, E. M. Simonsick, L. Ferrucci et al., "A short physical performance battery assessing lower extremity function: association with self-reported disability and prediction of mortality and nursing home admission," Journals of Gerontology, vol. 49, no. 2, pp. M85-M94, 1994.

[49] J. M. Guralnik, L. Ferrucci, C. F. Pieper et al., "Lower extremity function and subsequent disability: consistency across studies, predictive models, and value of gait speed alone compared with the short physical performance battery," Journals of Gerontology A: Biological Sciences and Medical Sciences, vol. 55, no. 4, pp. M221-M231, 2000.

[50] A. J. Cameron, R. A. Sicree, P. Z. Zimmet et al., "Cut-points for waist circumference in Europids and South Asians," Obesity, vol. 18, no. 10, pp. 2039-2046, 2010.

[51] B. Bogin, M. Kapell, M. V. Silva, A. Orden, P. Smith, and J. Loucky, "How Genetic are Human Body Proportions?" Perspect Human Growth Development Mature, pp. 205-221, 2001.

[52] B. Bogin, P. Smith, A. B. Orden, M. I. V. Silva, and J. Loucky, "Rapid change in height and body proportions of Maya American children," American Journal of Human Biology, vol. 14, no. 6, pp. 753-761, 2002.

[53] WHO Expert Consultation, "Appropriate body-mass index for Asian populations and its implications for policy and intervention strategies," The Lancet, vol. 363, no. 9403, pp. 157-163, 2004.

[54] J. Vermeulen, J. C. L. Neyens, E. van Rossum, M. D. Spreeuwenberg, and L. P. de Witte, "Predicting ADL disability in community-dwelling elderly people using physical frailty indicators: a systematic review," BMC Geriatrics, vol. 11, p. 33, 2011.

[55] D. Balzi, F. Lauretani, A. Barchielli et al., "Risk factors for disability in older persons over 3-year follow-up," Age and Ageing, vol. 39, no. 1, Article ID afp209, pp. 92-98, 2009.

[56] B. Bogin, Patterns of Human Growth, Cambridge University Press, Cambridge, Mass, USA, 2nd edition, 1999.

[57] L. M. Jantz and R. L. Jantz, "Secular change in long bone length and proportion in the United States, 1800-1970," American Journal of Physical Anthropology, vol. 110, pp. 57-67, 1999.

[58] I. Duyar and C. Pelin, "Body height estimation based on tibia length in different stature groups," American Journal of Physical Anthropology, vol. 122, no. 1, pp. 23-27, 2003.

[59] J. M. Guralnik, S. Butterworth, M. E. J. Wadsworth, and D. Kuh, "Childhood socioeconomic status predicts physical functioning 
a half century later," The Journals of Gerontology A: Biological Sciences and Medical Sciences, vol. 61, no. 7, pp. 694-701, 2006.

[60] National Institute of Population Research and Training Demographic and Health Survey, Bangladesh, 2001.

[61] C. A. Northrop-Clewes, E. K. Rousham, C. G. N. Mascie-Taylor, and P. G. Lunn, "Anthelmintic treatment of rural bangladeshi children: effect on host physiology, growth, and biochemical status," American Journal of Clinical Nutrition, vol. 73, no. 1, pp. 53-60, 2001.

[62] R. Alam, J. B. Alam, M. M. Hasan, S. R. Das, K. Rahman, and B. K. Banik, "Study of water quality of sylhet city and its reasturants," Iranian Journal of Environmental Health Science \& Engineering, vol. 3, pp. 9-18, 2006.

[63] A. Núñez-de la Mora, R. T. Chatterton, O. A. Choudhury, D. A. Napolitano, and G. R. Bentley, "Childhood conditions influence adult progesterone levels," PLOS Medicine, vol. 4, no. 5, p. e167, 2007.

[64] A. Núñez-De La Mora, G. R. Bentley, O. A. Choudhury, D. A. Napolitano, and R. T. Chatterton, "The impact of developmental conditions on adult salivary estradiol levels: why this differs from progesterone?" American Journal of Human Biology, vol. 20, no. 1, pp. 2-14, 2008.

[65] National Institute of Population Research and Training and B. Dhaka, "Bangladesh Demographic and Health Survey," Preliminary Report, Calverton, Md, USA, 2012.

[66] T. Ahmed, M. Mahfuz, S. Ireen et al., "Nutrition of children and women in Bangladesh: trends and directions for the future," Journal of Health, Population and Nutrition, vol. 30, no. 1, pp. 1$11,2012$.

[67] C. Quintana-Domeque, C. Bozzoli, and M. Bosch, "Infant mortality and adult stature in Spain," Social Science \& Medicine, vol. 72, no. 11, pp. 1893-1903, 2011.

[68] R. G. Westendorp and T. B. Kirkwood, "Human longevity at the cost of reproductive success," Nature, vol. 396, pp. 743-746, 1998.

[69] G. Doblhammer and J. Oeppen, "Reproduction and longevity among the British peerage: the effect of frailty and health selection," Proceedings of the Royal Society, vol. 270, no. 1524, pp. 1541-1547, 2003.

[70] N. S. Gavrilova, L. A. Gavrilov, V. G. Semyonova, and G. N. Evdokushkina, "Does exceptional human longevity come with a high cost of infertility? Testing the evolutionary theories of aging," Annals of the New York Academy of Sciences, vol. 1019, pp. 513-517, 2004.

[71] M. Kuningas, S. Altmäe, A. G. Uitterlinden, A. Hofman, C. M. van Duijn, and H. Tiemeier, "The relationship between fertility and lifespan in humans," Age, vol. 33, no. 4, pp. 615-622, 2011.

[72] F. Saibene and A. E. Minetti, "Biomechanical and physiological aspects of legged locomotion in humans," European Journal of Applied Physiology, vol. 88, no. 4-5, pp. 297-316, 2003.

[73] K. M. Beavers, M. E. Miller, W. J. Rejeski, B. J. Nicklas, and S. B. Krichevsky, "Fat mass loss predicts gain in physical function with intentional weight loss in older adults," The Journals of Gerontology A: Biological Sciences and Medical Sciences, vol. 68, no. 1, pp. 80-86, 2013.

[74] M. A. Denvir and G. A. Gray, "Run for your life: exercise, oxidative stress and the ageing endothelium," The Journal of Physiology, vol. 587, pp. 4137-4138, 2009.

[75] Department of Health, UK Physical Activity Guidelines, London, UK, 2011.
[76] L. Khan, Bangladeshis in Loughborough 1990, Leicestershire County Council, Leicester, UK, 1990.

[77] K. Gardner, "Keeping connected: security, place, and social capital in a 'Londoni' village in Sylhet," Journal of the Royal Anthropological Institute, vol. 14, no. 3, pp. 477-495, 2008.

[78] C. R. Victor, V. Burholt, and W. Martin, "Loneliness and ethnic minority elders in Great Britain: an exploratory study," Journal of Cross-Cultural Gerontology, vol. 27, no. 1, pp. 65-78, 2012.

[79] S. Asghar, A. Magnusson, A. Khan, K. Ali, and A. Hussain, "In Bangladesh, overweight individuals have fewer symptoms of depression than nonoverweight individuals," Obesity, vol. 18, no. 6, pp. 1143-1145, 2010.

[80] A. Lucas, E. Murray, and S. Kinra, "Heath beliefs of UK South Asians related to lifestyle diseases: a review of qualitative literature," Journal of Obesity, vol. 2013, Article ID 827674, 13 pages, 2013.

[81] Welsh Government, 2012, No Title, Welsh Gov Fly Start. 

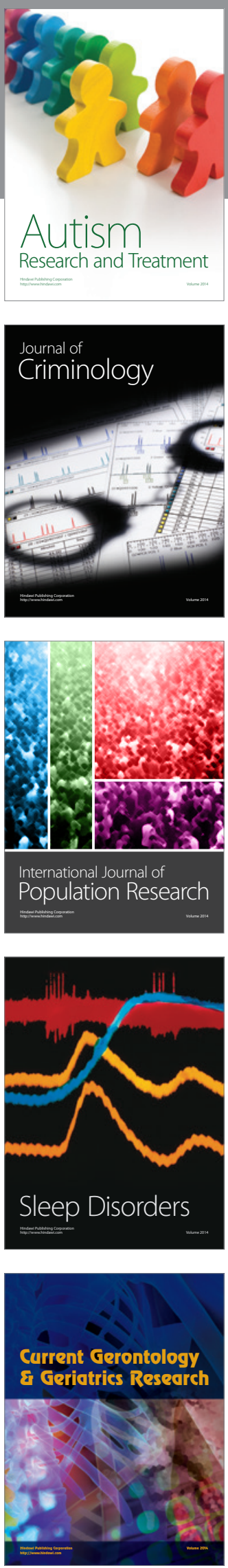
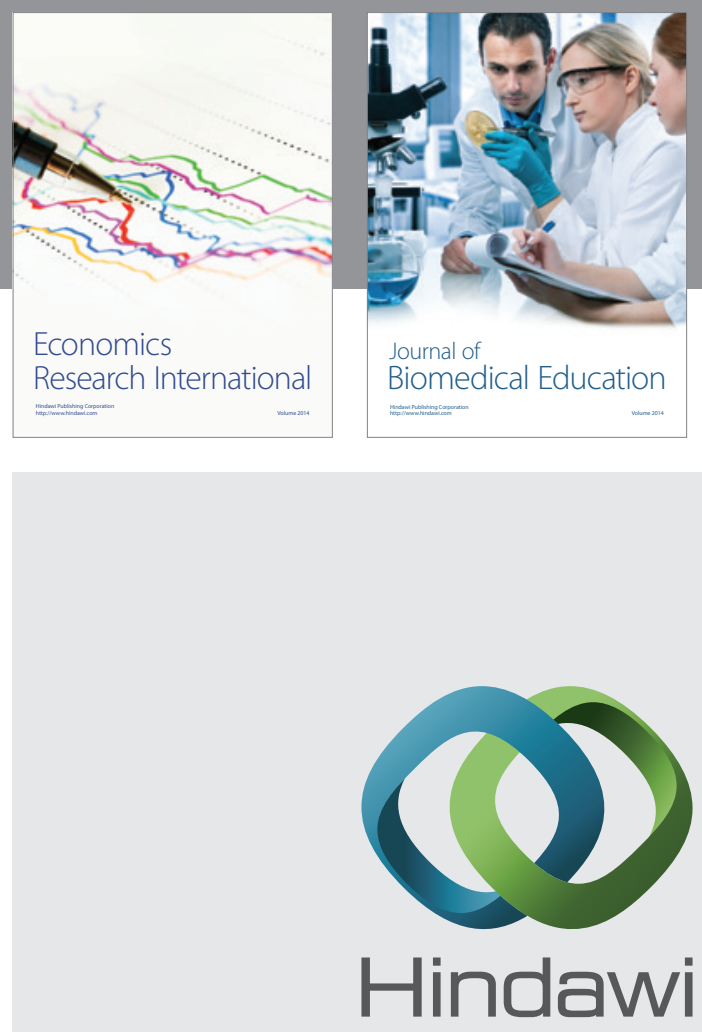

Submit your manuscripts at

http://www.hindawi.com
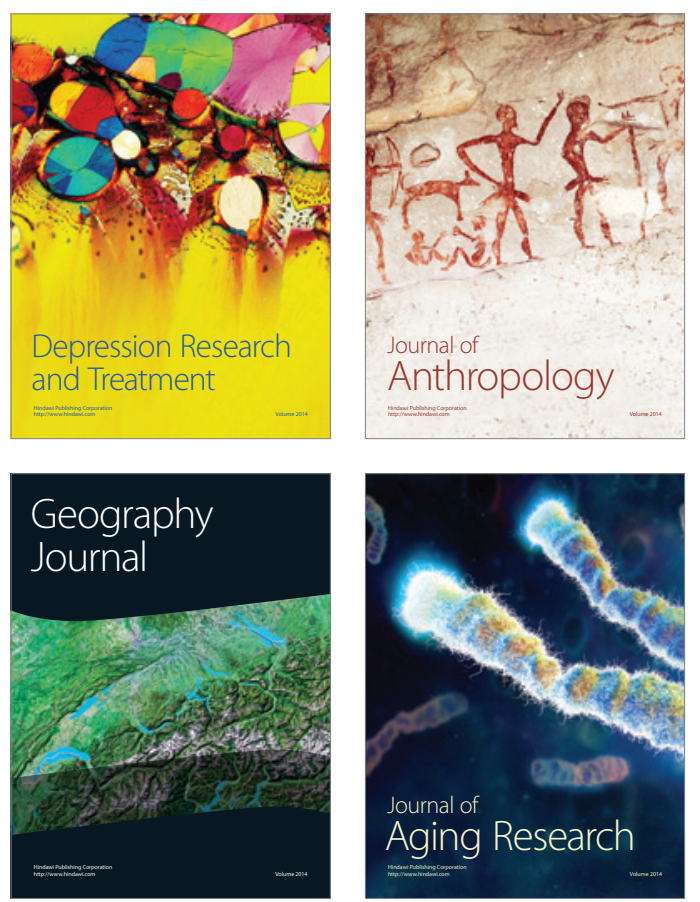
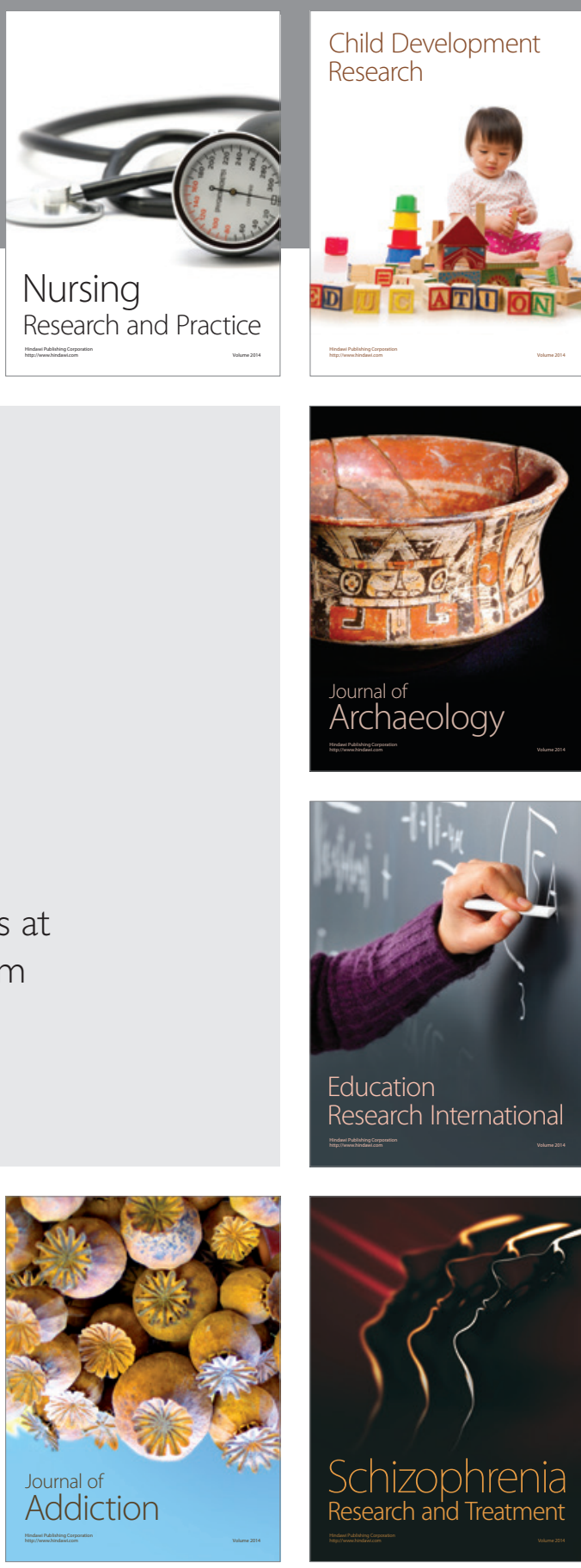

(D)
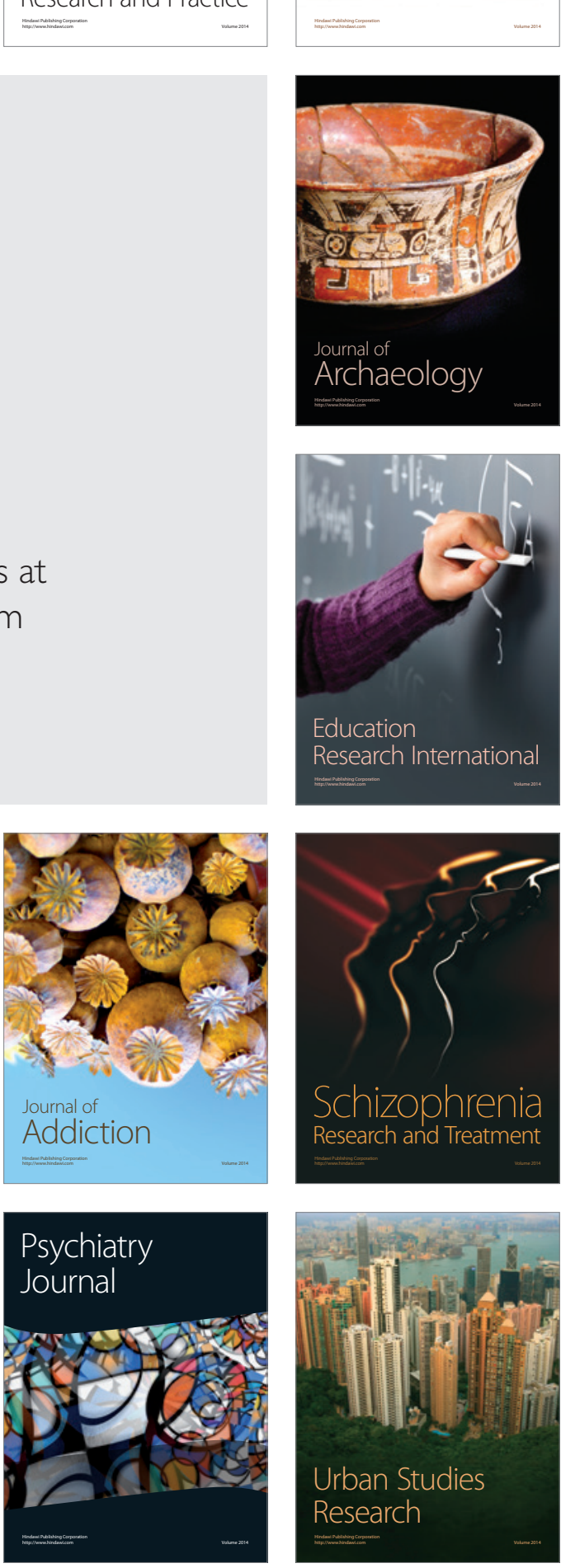